\title{
Mysteries behind the Low Salinity Water Injection Technique
}

\author{
Emad Waleed Al-Shalabi, Kamy Sepehrnoori, and Gary Pope \\ Department of Petroleum and Geosystems Engineering, The University of Texas at Austin, Austin, TX 78712, USA
}

Correspondence should be addressed to Emad Waleed Al-Shalabi; ealshalabi@utexas.edu

Received 25 October 2013; Accepted 22 April 2014; Published 25 May 2014

Academic Editor: Alireza Bahadori

Copyright (C) 2014 Emad Waleed Al-Shalabi et al. This is an open access article distributed under the Creative Commons Attribution License, which permits unrestricted use, distribution, and reproduction in any medium, provided the original work is properly cited.

\begin{abstract}
Low salinity water injection (LSWI) is gaining popularity as an improved oil recovery technique in both secondary and tertiary injection modes. The objective of this paper is to investigate the main mechanisms behind the LSWI effect on oil recovery from carbonates through history-matching of a recently published coreflood. This paper includes a description of the seawater cycle match and two proposed methods to history-match the LSWI cycles using the UTCHEM simulator. The sensitivity of residual oil saturation, capillary pressure curve, and relative permeability parameters (endpoints and Corey's exponents) on LSWI is evaluated in this work. Results showed that wettability alteration is still believed to be the main contributor to the LSWI effect on oil recovery in carbonates through successfully history matching both oil recovery and pressure drop data. Moreover, tuning residual oil saturation and relative permeability parameters including endpoints and exponents is essential for a good data match. Also, the incremental oil recovery obtained by LSWI is mainly controlled by oil relative permeability parameters rather than water relative permeability parameters. The findings of this paper help to gain more insight into this uncertain IOR technique and propose a mechanistic model for oil recovery predictions.
\end{abstract}

\section{Introduction}

Oil recovery from carbonate rocks is a challenge due to the high fracture density and the rock wettability state which ranges from mixed-wet to oil-wet. One of the recently recommended improved oil recovery (IOR) techniques is low salinity water injection (LSWI), which is believed to shift the wettability state of the rock towards more water-wet state. The LSWI technique has several advantages including high efficiency in displacing light to medium gravity crude oils, ease of injection into oil-bearing formations, availability and affordability of water, and lower capital and operating costs compared to other IOR methods, which leads to favorable economics. Other names proposed in the literature for the same mechanism are LoSal, Smart Waterflood, and Advanced Ion Management. The LSWI effect on oil recovery from carbonates was shown both at laboratory scale and to a limited extent at field scale. Although most researchers believe that wettability alteration is the main mechanism for the LSWI on oil recovery from carbonates, there are others who believe in the presence of other contributing mechanisms. Therefore, work is still progressing to understand the chemical interactions in crude oil-brine-rock (COBR) in the porous media.

The LSWI effect on oil recovery from carbonate is not well addressed compared to sandstone rocks due to the previous thoughts of relating wettability alteration by low salinity water to the presence of clay, which is not the case in carbonate rocks. Nevertheless, the effect of LSWI on oil recovery from carbonate rocks was investigated at laboratory scale using both spontaneous imbibition and coreflooding studies.

Høgnesen et al. [1] concluded from their spontaneous imbibition experiments on reservoir limestone cores that increasing sulfate ion concentration at high temperature leads to oil recovery increase due to the role of sulfate ion as a wettability modifying agent for carbonate rocks from mixedwet to water-wet state. Webb et al. [2] investigated the effect of sulfate on oil recovery from North Sea carbonate core samples through spontaneous imbibition experiments. They reported that seawater has the ability to alter wettability of the carbonate system to more water-wet state compared to sulfate-free water. Zhang et al. [3] studied wettability alteration of North Sea chalk reservoirs in Ekofisk field showing the effect of adding calcium and/or magnesium 
ions at various temperatures. They concluded that wettability alteration occurs if the imbibing water contains either $\mathrm{Ca}^{2+}$ and $\mathrm{SO}_{4}{ }^{2-}$ or $\mathrm{Mg}^{2+}$ and $\mathrm{SO}_{4}{ }^{2-}$. Moreover, Strand et al. [4] observed 15\% increase in oil recovery from limestone cores when seawater was imbibed compared to seawater free of sulfate. Increased oil recovery using low salinity water injection in limestone formations was noticed by Fjelde [5].

Bagci et al. [6] reported high oil recovery of $35.5 \%$ of OOIP from their corefloods by using $2 \mathrm{wt} \% \mathrm{KCl}$ on limestone cores and high $\mathrm{pH}$ effluent brine due to ions exchange reactions with the clay present in the rock. They considered wettability alteration as the reason behind recovering more oil without further explanation. Yousef et al. [7] investigated the applicability of low salinity water injection (Smart Waterflood) on carbonate rocks for improving oil recovery by using different dilutions of seawater. The results of coreflooding tests showed increasing oil recovery with stepwise dilution of seawater upon which $18 \%$ incremental oil recovery was achieved due to tertiary water injection. Coreflooding experiments on both dolomite cores from West Texas and limestone cores from the Middle East were performed by Gupta et al. [8]. Experiments showed incremental 5-9\% OOIP recovery from both dolomite and limestone cores as a result of adding sulfate ions. For limestone cores, 7-9\% OOIP was obtained due to reducing hardness of the injected water, not the total dissolved solids. Another interesting finding is the $15 \%$ and $20 \%$ OOIP by using borate $\left(\mathrm{BO}_{3}{ }^{3-}\right)$ and phosphate $\left(\mathrm{PO}_{4}{ }^{3-}\right)$ as modified ions, respectively. In a later work, Yousef et al. [9] demonstrated that wettability alteration is the reason behind LSWI through NMR, contact angle measurement, and zeta potential studies. The results showed that wettability alteration occurs through changing the surface charge from the zeta potential measurements and dissolution of $\mathrm{CaSO}_{4}$ from NMR tests.

Al-Harrasi et al. [10] provided direct evidence of low salinity water flooding effect on oil recovery from Omani carbonate rocks through spontaneous and coreflooding experiments. Wettability alteration was referred to as the reason for low salinity water injection with negligible reduction in interfacial tension. Also, they reported that low salinity water injection by lowering the ionic strength has more pronounced effect on oil recovery from oil-bearing zone cores compared to hardening the injected water. Nevertheless, the case is just the opposite for Stevns Klint outcrop chalk cores because they are more responsive to hardening of the injected low salinity water as was reported by Romanuka et al. [11] through their spontaneous imbibition experiments.

Extensive research was performed by Austad and coworkers [12-14] which showed the possibility of wettability alteration and enhancing oil recovery from carbonate rocks by modifying the ionic composition in the injected water. Wettability alteration is the main and most acceptable mechanism for the incremental oil recovery obtained from carbonate rocks using LSWI. Wettability alteration in carbonate rocks using smart water can be achieved by injecting water containing $\mathrm{SO}_{4}{ }^{2-}$ and either $\mathrm{Ca}^{2+}$ or $\mathrm{Mg}^{2+}$ or both of them in the presence of high temperatures $\left(>90^{\circ} \mathrm{C}\right)$. It was proposed that, with increasing temperature, the affinity of sulfate to chalk rock surface increases and sulfate adsorption occurs. At the same time, $\mathrm{Ca}^{2+}$ adsorption increases as well, as the initial positive charge of the rock decreases. Hence, more excess $\mathrm{Ca}^{2+}$ ions are present close to the surface which reacts with the carboxylic material and releases some of them. Moreover, with increasing the temperature $\mathrm{Mg}^{2+}$ becomes more active, $\mathrm{Ca}^{2+}$ substitution by $\mathrm{Mg}^{2+}$ occurs, and sulfate becomes less active as it reacts with $\mathrm{Mg}^{2+}$. Otherwise, $\mathrm{CaSO}_{4}$ precipitation occurs which causes injection problems [13].

The first ever LoSal application in carbonate reservoirs was reported by Yousef et al. [15]. Two single-well chemical tracer tests (SWCTT) were applied in an upper jurassic carbonate reservoir using a diluted version of Qurayyah seawater. The tests resulted in about 7 saturation units' reduction in the residual oil beyond conventional seawater injection. The results obtained matched their previous experimental work which is encouraging to plan a multiwell demonstration pilot.

Only a few modeling works for carbonate rocks have been performed so far due to various reasons. These reasons include the complex chemical interaction in rock-oil-brine and the heterogeneity of carbonate rocks, which complicate oil recovery predications by LSWI. Also, the uncertainty in the controlling mechanism and the clash in some of the published experimental results shifted the focus on experimental work rather than modeling work. This paper includes history-matching of Chandrasekhar and Mohanty's [16] experimental work using the UTCHEM simulator, which is a $3 \mathrm{D}$ multiphase flow, transport, and chemical flooding simulator for black oil, developed at The University of Texas at Austin.

\section{Experimental Data}

Chandrasekhar and Mohanty [16] conducted several vertical corefloods to investigate the low salinity water injection effect on oil recovery from Middle Eastern carbonate core plugs. The coreflood of our interest is the one with different injected seawater dilutions. Heterogeneous carbonate core plug was used with average porosity and liquid permeability of $26.4 \%$ and $7.59 \mathrm{mD}$, respectively. The coreflood was conducted at reservoir temperature of $248^{\circ} \mathrm{F}$ and atmospheric pressure at an injection rate of $1 \mathrm{ft} /$ day. At each injection cycle, the injection rate was increased to $10 \mathrm{ft} /$ day to make sure that the oil maximum recovery was reached. The brines used were field water of 179,726 ppm and different diluted versions of seawater of $43,619 \mathrm{ppm}$ by weight. Rock properties and fluid properties are shown in Tables 1,2, and 3. The oil recovery and pressure drop data are shown in Figures 1 and 2. Here an increase in oil recovery is observed with stepwise dilution of the seawater by tertiary water injection. More details about the experimental work are described elsewhere [16]. The UTCHEM software was used to history-match both oil recovery and pressure drop data. The pressure drop data of each injection cycle is matched just for the low injection rate $(1 \mathrm{ft} /$ day). The second injection cycle is an exception, where the pressure drop is matched for both injection rates (1 and $10 \mathrm{ft} /$ day) because of the incremental oil recovery obtained with increasing the rate at $10 \mathrm{ft} /$ day in this cycle. 
TABLE 1: Reservoir core properties (Chandrasekhar and Mohanty, 2013 [16]).

\begin{tabular}{lccc}
\hline Pore Volume & 15.8 & & $\mathrm{cc}$ \\
Porosity & & 0.264 & \\
Permeability & 7.59 & & $\mathrm{mD}$ \\
Diameter & 3.79 & & $\mathrm{~cm}$ \\
Cross Sectional Area & 11.28 & & $\mathrm{~cm}^{2}$ \\
Length & 5.3 & & $\mathrm{~cm}$ \\
$S_{w i}$ & & 0.3181 & \\
$S_{o i}$ & & 0.6819 & \\
\hline
\end{tabular}

TABLE 2: Field oil sample properties (Chandrasekhar and Mohanty, $2013[16])$.

\begin{tabular}{lcc}
\hline & Oil properties & \\
\hline Viscosity $(\mathrm{cp})$ at $248^{\circ} \mathrm{F}$ & 1.05 \\
Density $(\mathrm{g} / \mathrm{cc})$ at $248^{\circ} \mathrm{F}$ & 0.618 \\
API (degrees) & 40 \\
\hline
\end{tabular}

TABLE 3: Properties of various dilutions of seawater $\left(248^{\circ} \mathrm{F}\right)$ (Chandrasekhar and Mohanty, 2013 [16]).

\begin{tabular}{lcc}
\hline Injected water & $\begin{array}{c}\text { Water propertiesat } 248^{\circ} \mathrm{F} \\
\text { Water density } \\
\text { salinity }(\mathrm{gpm})\end{array}$ & $\begin{array}{c}\text { Water viscosity } \\
(\mathrm{cp})\end{array}$ \\
\hline 43619 & 0.9760 & 0.260 \\
21809.5 & 0.9595 & 0.246 \\
4361.9 & 0.9464 & 0.234 \\
2180.95 & 0.9448 & 0.233 \\
\hline
\end{tabular}

\section{Simulation Data}

This section includes both simulation model description and experimental data analysis to obtain the simulation inputs needed.

3.1. Simulation Model Description. A 2D Cartesian grid system was used with $10 \times 1 \times 10$ grid blocks to simulate the heterogeneous core plug for the coreflood. The decision on using a heterogeneous model is discussed later in the seawater cycle match section. The heterogeneous model was considered by generating permeability distribution with an arithmetic mean of $7.59 \mathrm{mD}$ and Dykstra Parson's coefficient of 0.85 . A spherical variogram and a log normal permeability distribution were used. The $y$-direction correlation length was assumed to be similar to the $x$-direction; however, a high $z$-direction correlation length compared to the $x$ direction was chosen, which generated vertical layers of different permeabilities (Figure 3). The simulation model has two horizontal wells, injector at the bottom and producer at the top. Table 4 shows length, width, and height dimensions for the grid blocks. We assumed a negligible capillary end effect.

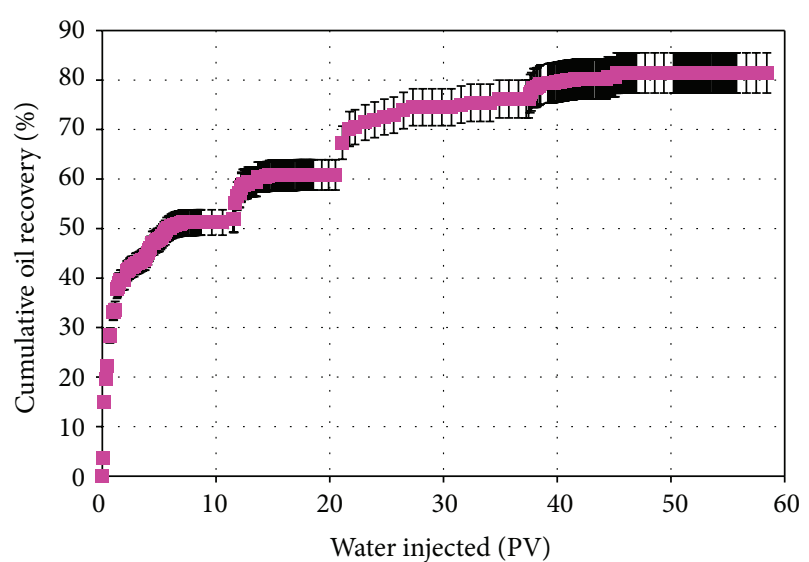

FIGURE 1: Cumulative oil recovery curve for the coreflood conducted [16].

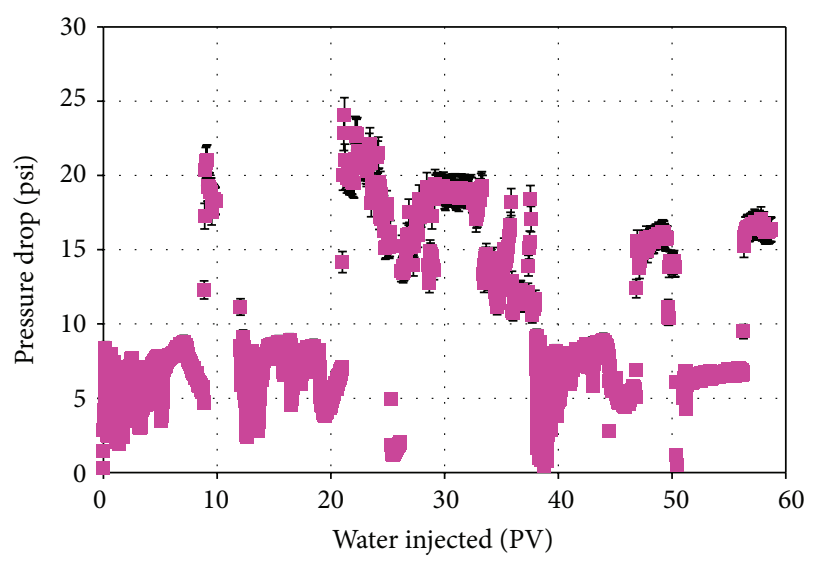

Figure 2: Pressure drop data for the coreflood conducted [16].

3.2. Experimental Data Analysis. This section includes a description of pressure drop data analysis and application of JBN method to find relative permeability curves for the seawater injected cycle.

3.2.1. Pressure Drop Data Analysis. As was previously mentioned, the analysis of the pressure drop curve (Figure 2) is performed for the $1 \mathrm{ft} /$ day injection rate, except for the second cycle where the injection rate of $10 \mathrm{ft} / \mathrm{day}$ resulted in additional oil recovery. The water endpoint relative permeability for each cycle at $1 \mathrm{ft} /$ day and even for the second cycle at $10 \mathrm{ft} /$ day can be calculated using Darcy's law and stabilized average pressure drop value. The oil endpoint relative permeability was provided experimentally for the seawater cycle $\left(K_{r_{o}}^{*}=0.203\right)$. Table 5 summarizes the obtained endpoint relative permeabilities for water and oil. Table 5 shows endpoint permeability calculation for the second cycle including both low salinity water injection and trapping number effects. We can see a slight decrease in the water endpoint relative permeability values for the LSWI effect in all injection cycles, which indicates the presence of wettability alteration by LSWI. 
TABLE 4: Heterogeneous core model data.

\begin{tabular}{lcc}
\hline Parameter & Value & Comments \\
\hline $\begin{array}{l}\text { Number of grid } \\
\text { blocks }\end{array}$ & 100 & $2 \mathrm{D}(10 \times 1 \times 10)$ \\
Grid block sizes & $x$-direction: $1-10, \Delta x$ is $0.0033588 \mathrm{~m}$ \\
$(\Delta I, \Delta J, \Delta K), \mathrm{m}$ & $y$-direction: $1-1, \Delta y$ is $0.033588 \mathrm{~m}$ \\
& $z$-direction: $1-10, \Delta z$ is $0.0053 \mathrm{~m}$ & Constant grid size in the $x$-, \\
Composite core & $0.033588 \mathrm{~m} \times 0.033588 \mathrm{~m} \times 0.053 \mathrm{~m}$ & - and $z$-direction. \\
model dimensions, $\mathrm{m}$ & & Length $\times$ width $\times$ height \\
\hline
\end{tabular}

TABLE 5: Endpoint relative permeability data analysis.

\begin{tabular}{|c|c|c|c|c|c|}
\hline Oil viscosity & 1.05 & $\mathrm{cP}$ & \multirow{3}{*}{ Oil-water IFT } & \multirow{3}{*}{30} & \multirow{3}{*}{ Dynes $/ \mathrm{cm}$} \\
\hline Composite core length & 5.3 & $\mathrm{~cm}$ & & & \\
\hline Cross-sectional area & 11.28 & $\mathrm{~cm}^{2}$ & & & \\
\hline Injection rate (main) & 0.045 & $\mathrm{cc} / \mathrm{min}$ & \multirow{2}{*}{$K_{o @ S w i r r}$} & \multirow{2}{*}{1.54} & \multirow{2}{*}{$\mathrm{mD}$} \\
\hline Absolute brine permeability & 7.59 & $\mathrm{mD}$ & & & \\
\hline Injection cycle & Water viscosity $(\mathrm{cP})$ & Pressure drop (psi) & $k_{r w}^{*}$ & $S_{\text {or }}$ & $k_{r o}^{*}$ \\
\hline First & 0.26 & 7.20 & 0.025 & 0.329 & 0.203 \\
\hline Second 1 (LSWI effect) & 0.246 & 7.00 & 0.024 & 0.267 & \\
\hline Second 2 (trapping number effect) & 0.246 & 18.90 & 0.089 & 0.163 & \\
\hline Third & 0.234 & 7.00 & 0.023 & 0.127 & \\
\hline Fourth & 0.233 & 7.20 & 0.022 & 0.127 & \\
\hline
\end{tabular}

3.2.2. JBN Method. Johnson, Bossler, and Naumann (JBN) method was applied to find relative permeability curves for the seawater cycle. The data obtained are shown in Figure 4; Corey's model was fitted to find relative permeability endpoints and exponents for the seawater cycle. Moreover, the analysis was taken a step further to calculate the fractional flow curve, upon which both mobility ratio and gravity effects are considered. The fractional flow in this case is defined as

$$
f_{w}=\frac{S^{n_{w}} M^{o}\left[1-N_{g}^{o}(1-S)^{n_{o}} \sin (\alpha)\right]}{S^{n_{w}} M^{o}+(1-S)^{n_{o}}} .
$$

The relative permeability data calculated from JBN method was fitted to an exponential function that was used later to calculate the fractional flow curve through mobility ratio calculations (Figure 5). The equation of relative permeability ratio as function of saturation is given by

$$
\frac{K_{r o}}{K_{r w}}=a e^{-b S_{w}} .
$$

The latter fractional flow curve (experimental) was matched with the analytical solution of fraction flow, where the main matching parameters are $n_{w}$ of 1.3 and $n_{o}$ of 3.5 (Figure 6). The water and oil endpoint relative permeability values were obtained using pressure drop curve analysis from Table 5 . The coreflood was conducted vertically which makes $\sin (\alpha)$ equal to 1 . The endpoint mobility ratio used is 0.47 and the endpoint gravity number is 0.01 . The definitions of endpoint mobility ratio $\left(M^{o}\right)$ and endpoint gravity number $\left(N_{g}^{o}\right)$ are given by

$$
\begin{gathered}
M^{o}=\frac{k_{r w}^{o} \mu_{o}}{k_{r o}^{o} \mu_{w}}, \\
N_{g}^{o}=\frac{k k_{r o}^{o} \Delta \rho g}{u \mu_{o}} .
\end{gathered}
$$

Nevertheless, there is a mismatch between the Buckley Leverett analytical solution compared to the experimental data provided by Chandrasekhar and Mohanty [16] (Figure 7). The main difference between the analytical solution and the experimental data is the heterogeneity effect which is not taken into account in analytical solution added to the capillary pressure effect. Both of these effects can be considered using the UTCHEM simulator to history-match the data.

\section{Results and Discussion}

This section covers seawater cycle history-matching and methods used for the wettability alteration effect matching for different dilutions of seawater injected cycles.

4.1. Seawater Cycle Match. The final set of relative permeability curves for the seawater cycle as a result of pressure drop analysis and JBN method is shown in Figure 8. The figure shows a weakly oil-wet rock, where $k_{r o}^{*}$ is $0.203, k_{r w}^{*}$ is $0.025, n_{o}$ is $3.5, n_{w}$ is 1.3 , and the intersection point is at about 0.5 water saturation. The heterogeneity effect was taken into consideration by applying a Dykstra Parson coefficient of 


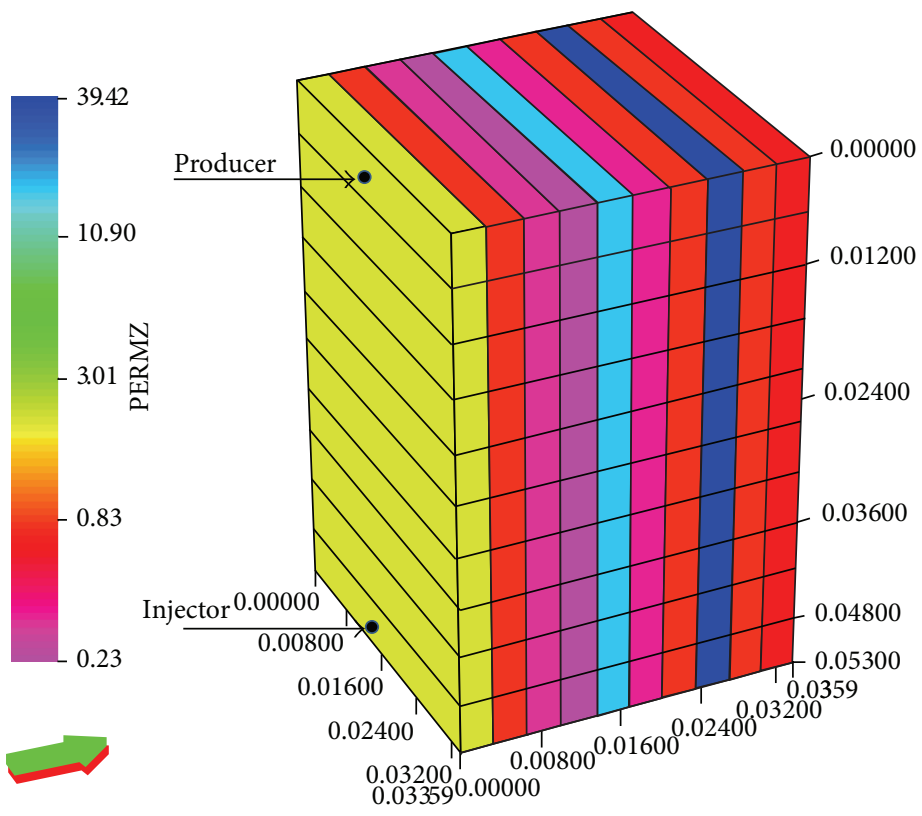

FIGURE 3: Simulation model used in different runs with heterogeneous permeability.

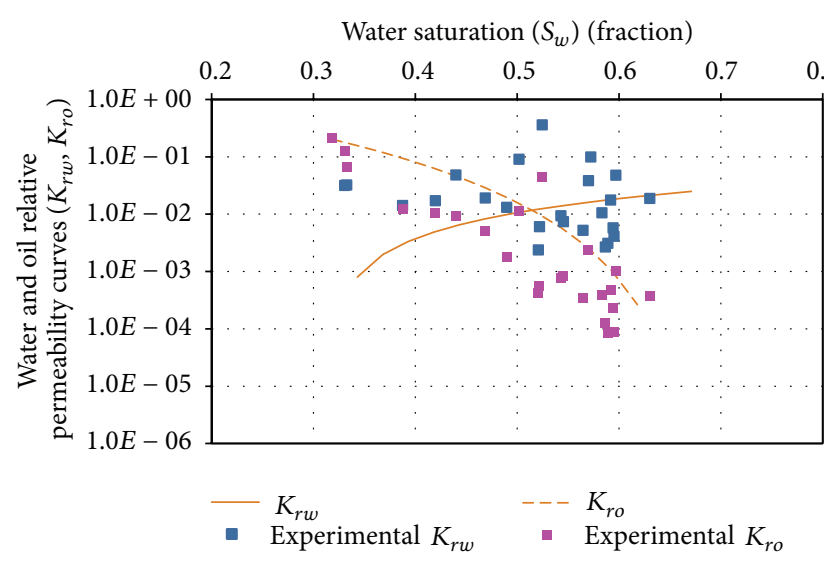

FIGURE 4: Relative permeability data analysis using the JBN method (first cycle).

0.85 along with correlation lengths which resulted in vertical layers of different permeabilities as was previously shown in Figure 3. Moreover, the capillary pressure contribution was considered by applying Brooks-Corey model for imbibition capillary pressure for mixed-wet rocks as follows.

(i) Water-wet part of capillary pressure curve $\left(S<S^{*}\right)$ is

$$
P_{c 12}=\mathrm{CPC}_{1} \sqrt{\frac{\phi}{k}}\left(\frac{S_{w}^{*}-S_{w}}{S_{w}^{*}-S_{w r}}\right)^{\mathrm{EPC}_{1}}
$$

(ii) Oil-wet part of capillary pressure curve $\left(S>S^{*}\right)$ is

$$
P_{c 12}=\mathrm{CPC}_{2} \sqrt{\frac{\phi}{k}}\left(\frac{S_{w}-S_{w}^{*}}{1-S_{o r}-S_{w}^{*}}\right)^{\mathrm{EPC}_{2}},
$$

TABLE 6: Summary of relative permeability and capillary pressure parameters (seawater cycle).

\begin{tabular}{lccc}
\hline \multicolumn{4}{c}{ Seawater cycle match parameters } \\
\hline \multicolumn{4}{c}{ Relative permeability parameters } \\
$k_{r w}{ }^{*}$ & 0.025 & $n_{w}$ & 1.3 \\
$k_{r o}{ }^{*}$ & 0.203 & $n_{o}$ & 3.5 \\
& \multicolumn{1}{c}{ Capillary pressure parameters } \\
$\mathrm{CPC}_{w}$ & 2 & $\mathrm{EPC}_{w}$ & \\
$\mathrm{CPC}_{o}$ & -2 & $\mathrm{EPC}_{o}$ & 2 \\
$S^{*}$ & & 0.5 & 2 \\
\hline
\end{tabular}

where CPC is a parameter related to the maximum capillary pressure, EPC is capillary pressure exponent, and $S^{*}$ is the water saturation at zero capillary pressure value. The capillary pressure curve used in matching oil recovery and pressure drop data along with summary of capillary pressure parameters and relative permeability parameters is presented in Figure 9 and Table 6, respectively. History-matching of oil recovery and pressure drop data showed that the $\mathrm{CPC}_{2}$ parameter controls the ultimate oil recovery value; however, $\mathrm{CPC}_{1}$ controls the initial hump of the oil recovery and the pressure drop data match. It can be seen clearly that the capillary pressure does not contribute much to data history-matching. Hence, the capillary pressure is neglected for history-matching the successive dilutions of seawater injection.

The results of history-matching of oil recovery and pressure drop data are depicted in Figures 10 and 11, respectively. In the latter figures, two curves are presented for the homogeneous $1 \mathrm{D}$ model with an average permeability and heterogeneous models. The history-matching shows the importance 


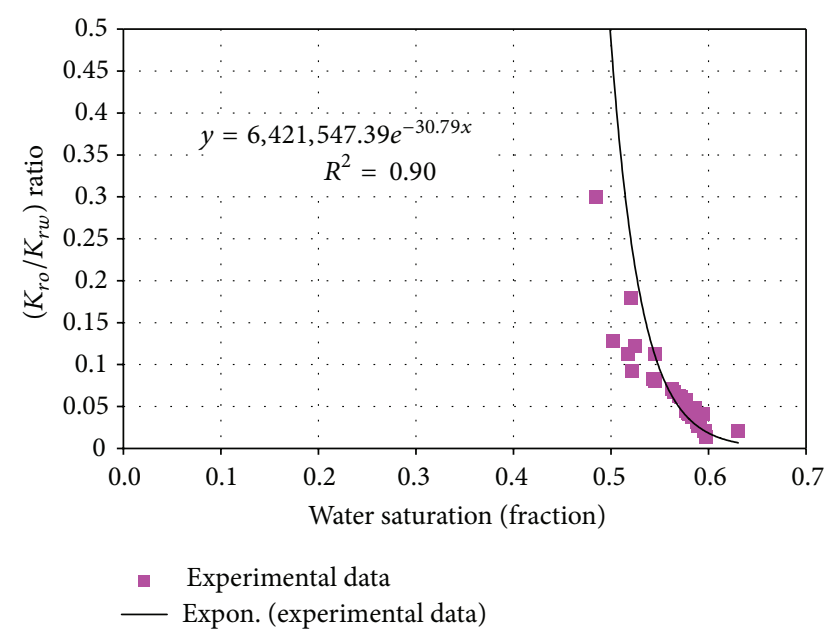

FIGURE 5: Relative permeability ratio versus water saturation (first cycle).

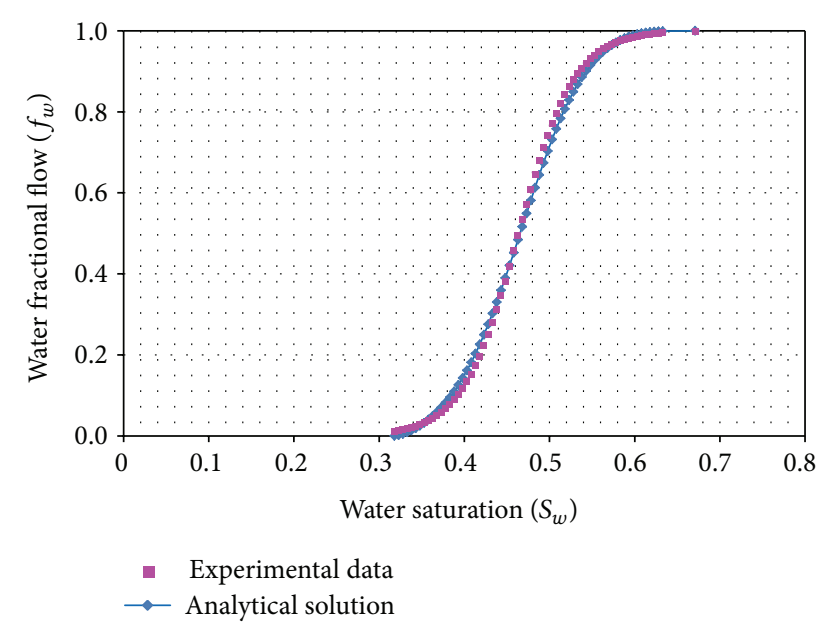

FIGURE 6: Fractional flow curve history-match (first cycle).

of heterogeneity incorporation to match reasonably the oil recovery and pressure drop curves.

4.2. Dilutions of Seawater Injected Cycles Match. This section includes history-matching of the LSWI cycles of Chandrasekhar and Mohanty [16] coreflood using two proposed methods.

4.2.1. First Method. In this method, seawater cycle's relative permeability parameters are used for the different dilution cycles, while only changing the residual oil saturation for each cycle based on the reported values. As expected, history-matching of data is not possible using this method which validates the necessity of tuning relative permeability parameters for LSWI cycles because $S_{\text {or }}$ contribution by itself is not enough. This is supported by the findings of oil recovery and pressure drop history-matching curves using this approach (Figures 12 and 13). It is worth mentioning that the jump in the second cycle of pressure drop curve

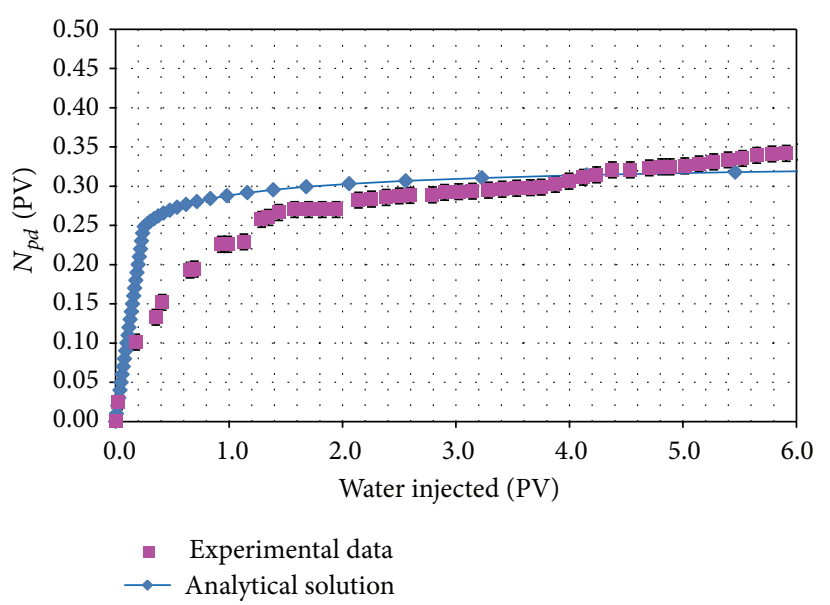

FIGURE 7: Buckley Leverett analytical solution (first cycle).

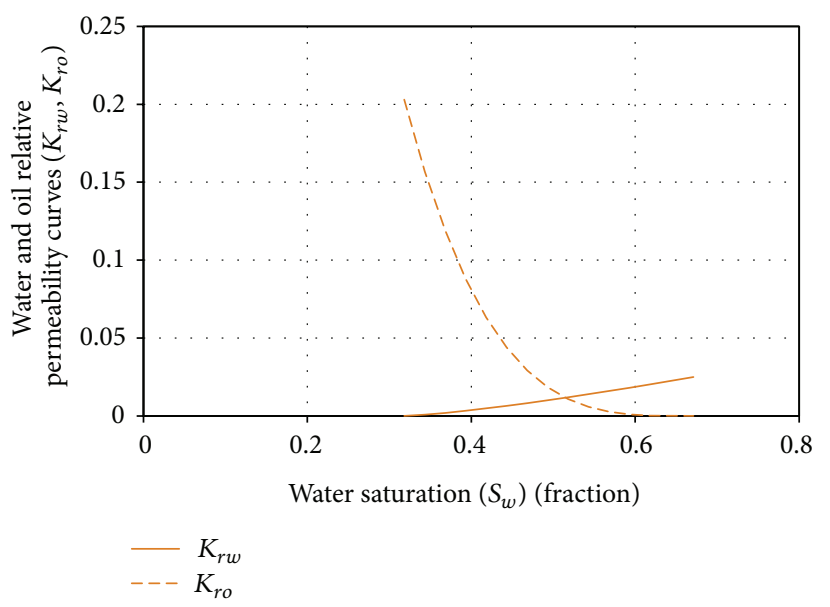

FIGURE 8: Relative permeability curves (first cycle).

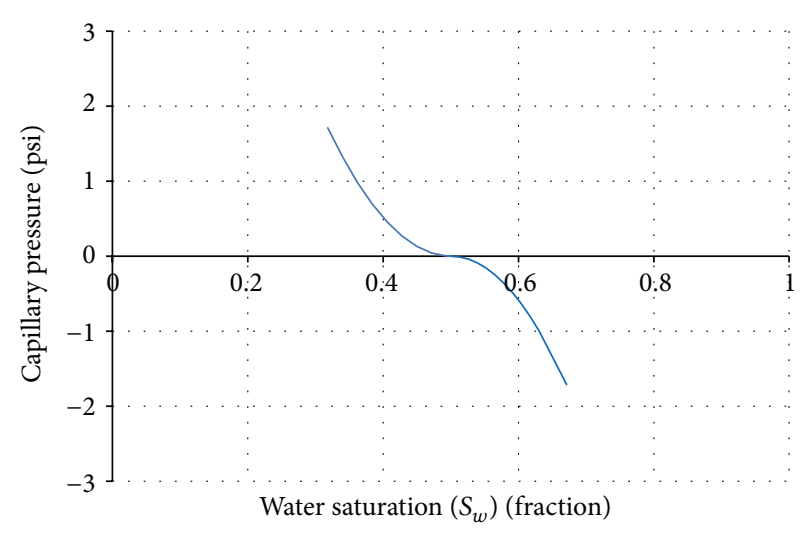

FIGURE 9: Capillary pressure curve (first cycle).

(Figure 13) is due to the trapping number effect as the injection rate was increased to $10 \mathrm{ft} / \mathrm{day}$ without changing the relative permeability parameters.

4.2.2. Second Method. This method includes three approaches: changing Corey's exponents only (first approach), 


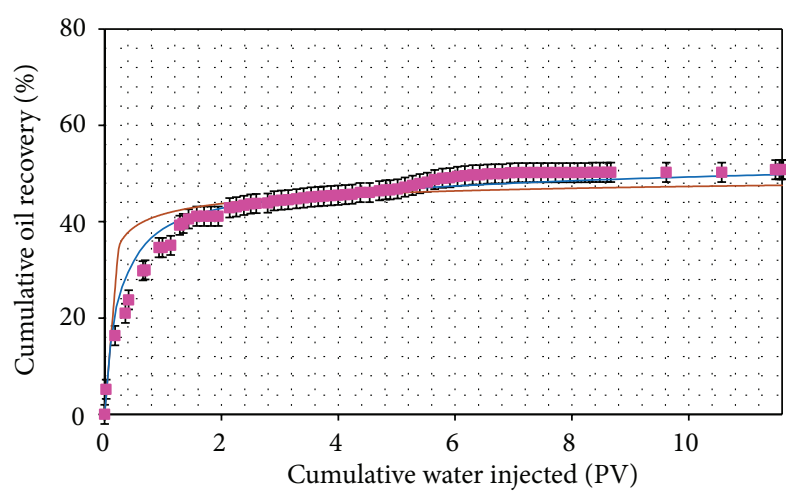

- Experimental data

- Homogeneous model

— Heterogeneous model

FIGURE 10: Oil recovery match for seawater cycle.

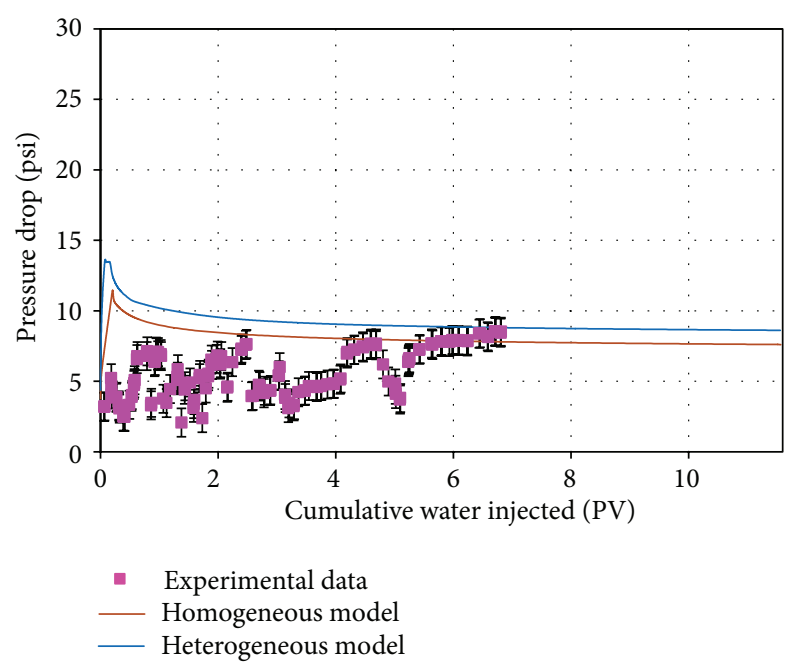

Figure 11: Pressure drop match for seawater cycle.

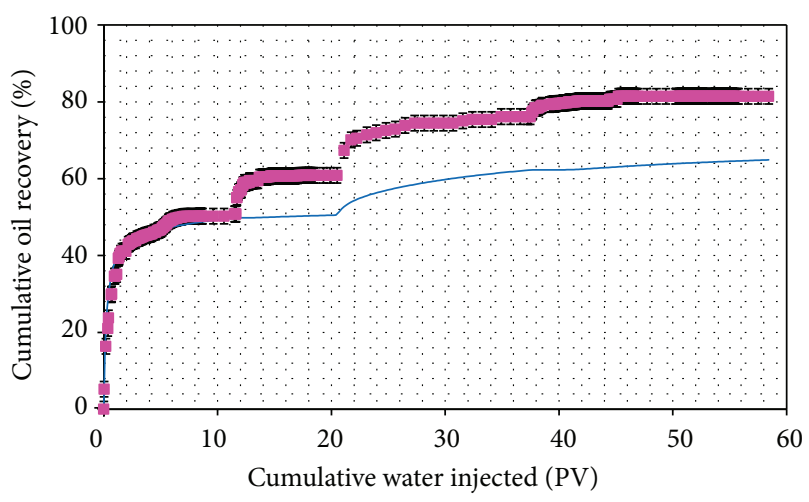

- Experimental data

- $S_{o r}$ contribution

FIGURE 12: Cumulative oil recovery match using the first method.

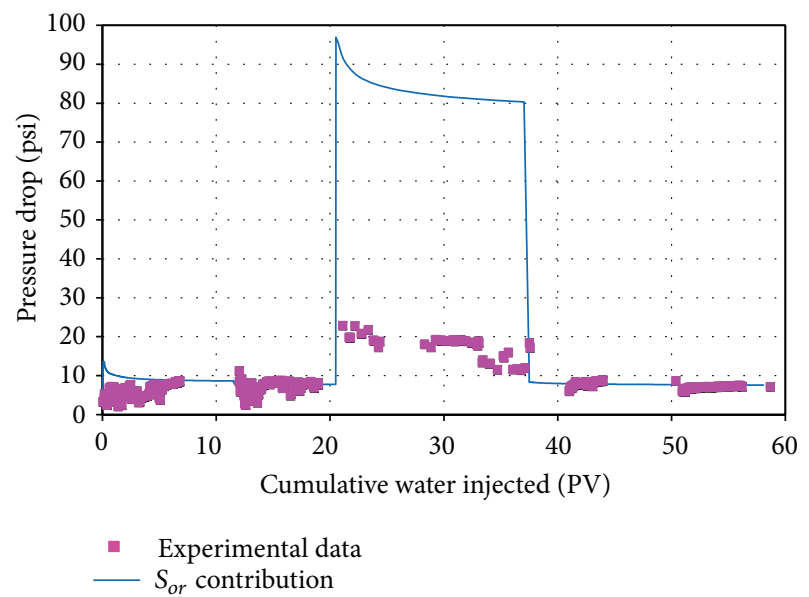

FIGURE 13: Overall pressure drop match using the first method.

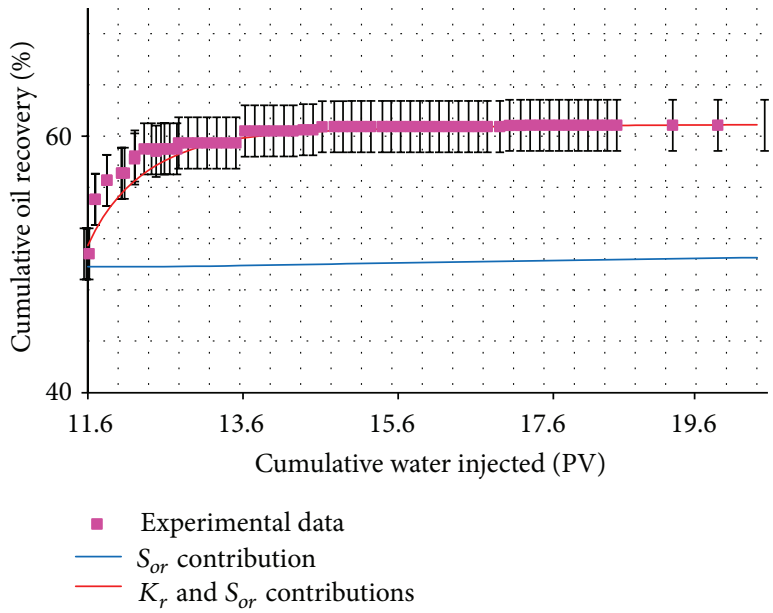

FIGURE 14: LSWI effect on second cycle oil recovery match using the second method (third approach).

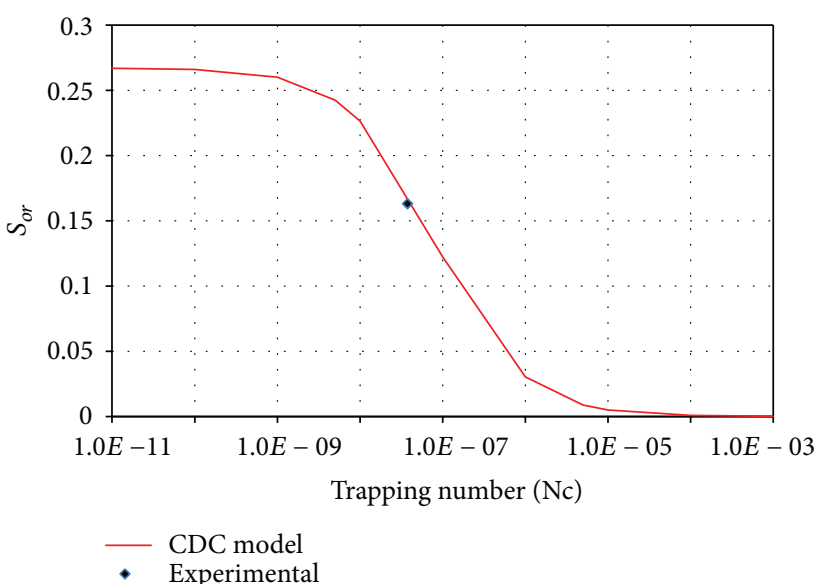

Figure 15: Modeled CDC curve for the coreflooding experiment. 


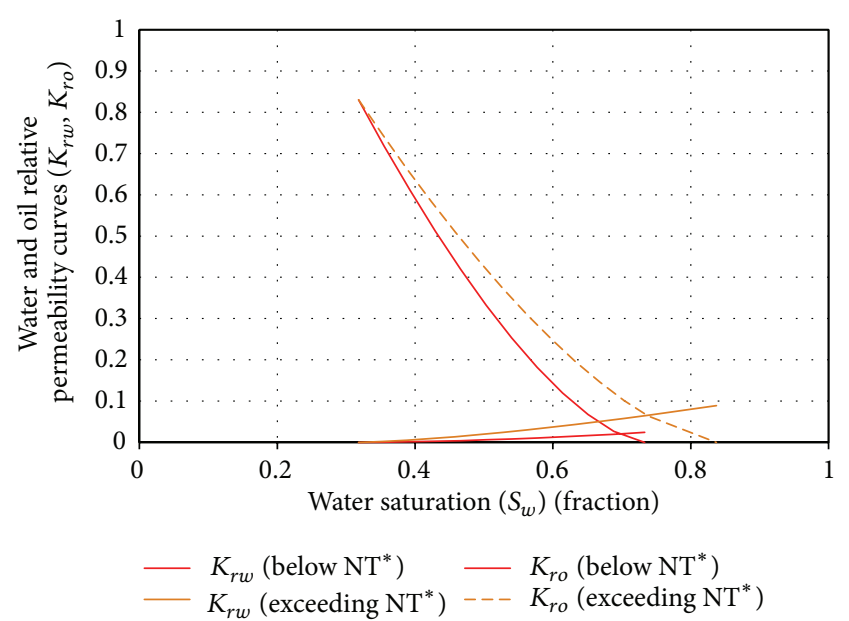

FIGURE 16: Relative permeability curves before and after exceeding critical $N_{T}$ (second cycle-trapping number).

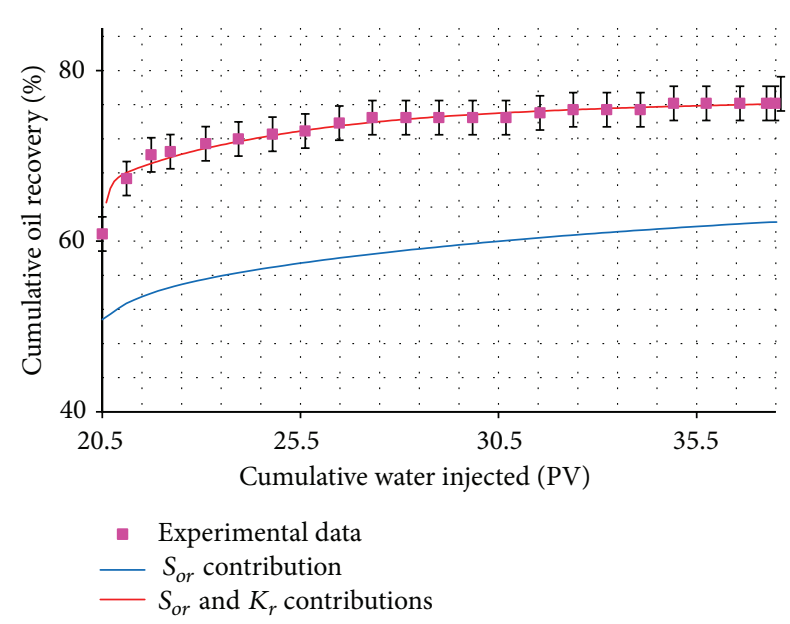

FIgURE 17: Trapping number effect on second cycle oil recovery match using the second method (third approach).

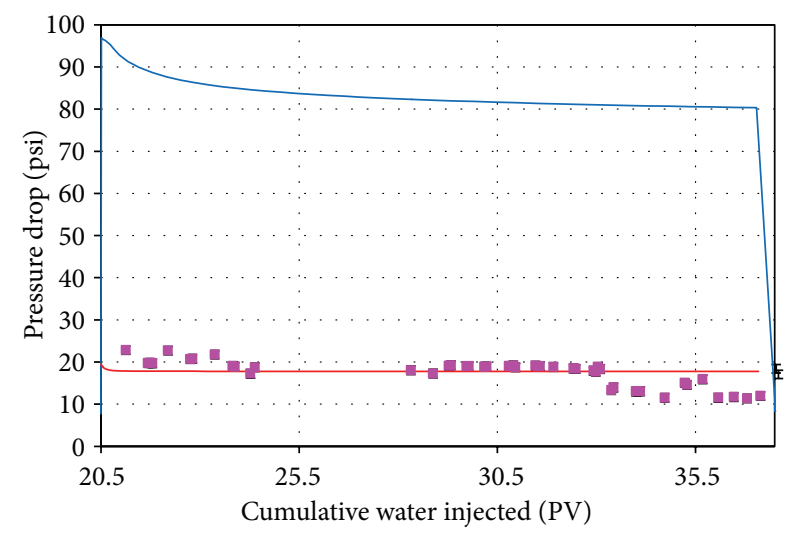

- Experimental data

- $S_{\text {or }}$ contribution

- $S_{o r}$ and $K_{r}$ contributions

FIGURE 18: Trapping number effect on second cycle pressure drop match using the second method (third approach).

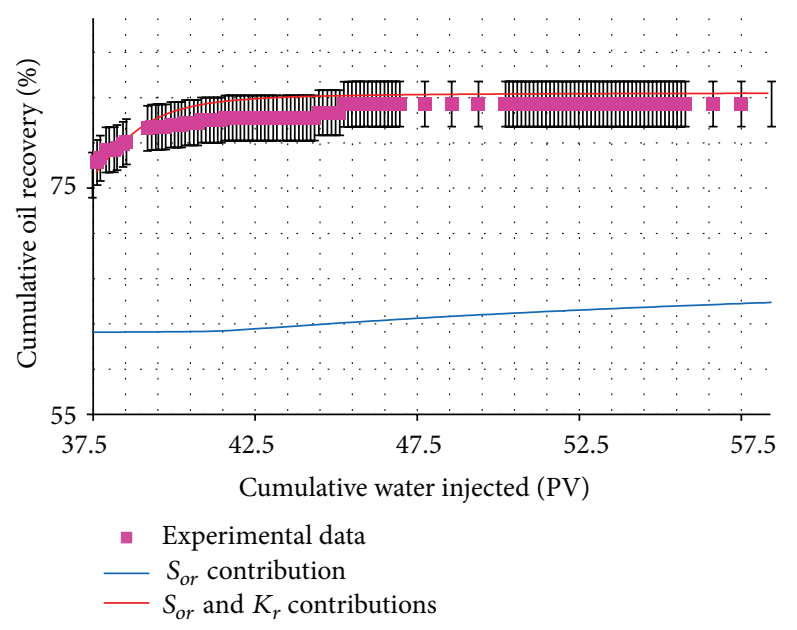

FIGURE 19: Third and fourth cycles oil recovery match using the second method (third approach).

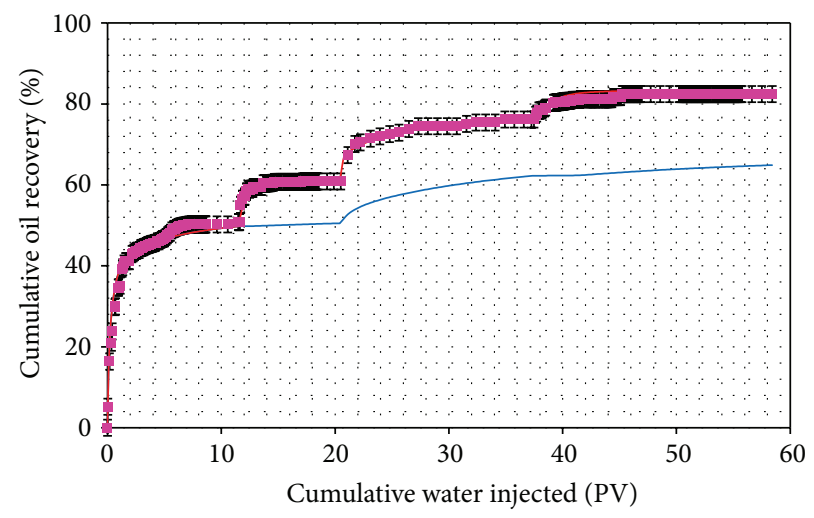

- Experimental data

- $S_{\text {or }}$ contribution

- $S_{o r}$ and $K_{r}$ contributions

FIGURE 20: Cumulative oil recovery match using the second method (third approach).

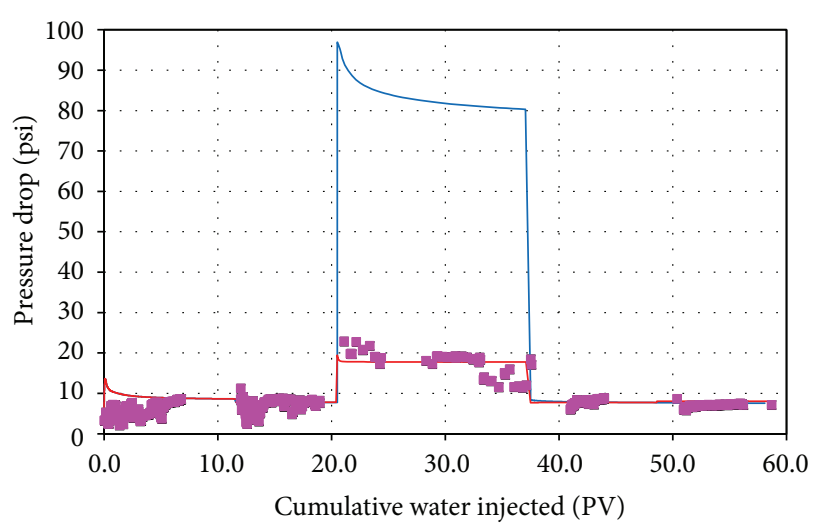

- Experimental data

- $S_{o r}$ contribution

- $S_{o r}$ and $K_{r}$ contributions

FIGURE 21: Overall pressure drop match using the second method (third approach). 


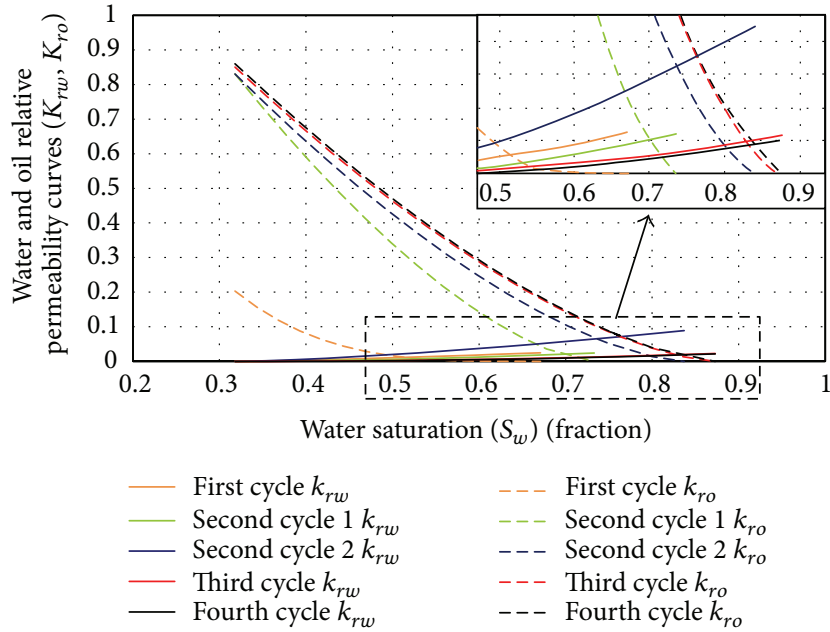

FIGURE 22: Relative permeability curves using the second method (third approach).

changing endpoint relative permeabilities only (second approach), and changing both Corey's exponents and endpoint relative permeabilities (third approach). The first two approaches were not successful in history-matching pressure drop and oil recovery data. The third approach of the second method is applied on Chandrasekhar and Mohanty [16] coreflood by tuning relative permeability parameters, including endpoints and Corey's exponents to match the data in each cycle starting with the second cycle. The $k_{r}$ and $S_{o r}$ contributions curve for the LSWI effect on the second cycle is shown in Figure 14.

The trapping number effect on the second cycle is considered using the capillary desaturation curve (CDC). The relation for adjusting residual oil saturation as a function of trapping number was proposed by Pope et al. [17] as follows:

$$
S_{l r}=S_{l r}^{\text {high }}+\frac{S_{l r}^{\text {low }}-S_{l r}^{\text {high }}}{1+T_{l} N_{T_{l}}^{\tau}}, \quad \text { for } l=1, \ldots, n p .
$$

Figure 15 shows the modeled CDC curve for the second cycle where the experimental trapping number calculated for the injection rate of $10 \mathrm{ft} / \mathrm{day}$ is matched using $S_{l r}^{\text {low }}$ of 0.267 , $S_{l r}^{\text {high }}$ of zero, $\tau$ of 0.82 , and $T_{l}$ parameter of 650,000 . The detailed calculations of the CDC curve are listed in Table 7. The effect of trapping number on relative permeability parameters was also considered using Delshad et al's [18] proposed model as follows:

$$
\begin{array}{r}
k_{r l}^{o}=k_{r l}^{\text {olow }}+\frac{S_{l^{\prime} r}^{\text {low }}-S_{l^{\prime} r}}{S_{l^{\prime} r}^{\text {low }}-S_{l^{\prime} r}^{\text {high }}}\left(k_{r l}^{\text {ohgh }}-k_{r l}^{\text {low }}\right), \\
\text { for } l, l^{\prime}=1, \ldots, n p, \\
n_{l}=n_{l}^{\text {low }}+\frac{S_{l^{\prime} r}^{\text {low }}-S_{l^{\prime} r}}{S_{l^{\prime} r}^{\text {low }}-S_{l^{\prime} r}^{\text {high }}}\left(n_{l}^{\text {high }}-n_{l}^{\text {low }}\right) \\
\text { for } l, l^{\prime}=1, \ldots, n p .
\end{array}
$$

TABLE 7: CDC curve parameters.

\begin{tabular}{lc}
\hline$S_{\text {or (high) }}$ & 0.000 \\
$S_{\text {or (low) }}$ & 0.267 \\
$T_{22}$ (parameter) & 650,000 \\
Tau $\left(N_{T}\right.$ exponent) & 0.82 \\
\hline$N_{T}$ & $S_{o r}$ \\
\hline $1.00 E-11$ & 0.267 \\
$1.00 E-11$ & 0.267 \\
$1.00 E-10$ & 0.266 \\
$1.00 E-09$ & 0.260 \\
$5.00 E-09$ & 0.242 \\
$\mathbf{1 . 0 0 E}-\mathbf{0 8}$ & $\mathbf{0 . 2 2 6}$ \\
$\mathbf{1 . 0 0 E}-\mathbf{0 7}$ & $\mathbf{0 . 1 2 2}$ \\
$1.00 E-06$ & 0.030 \\
$5.00 E-06$ & 0.009 \\
$1.00 E-05$ & 0.005 \\
$1.00 E-04$ & 0.001 \\
$1.00 E-03$ & 0.000 \\
\hline
\end{tabular}

TABLE 8: Relative permeability parameters before and after exceeding critical $N_{T}$.

\begin{tabular}{lccc}
\hline \multicolumn{4}{c}{ Second cycle matching parameters trapping number effect } \\
Below $N_{T}{ }^{*}$ (critical) & \multicolumn{2}{c}{ Exceeding $N_{T}{ }^{*}$ (critical) } \\
\hline$n_{w}$ & 1.7 & $n_{w}$ & 1.43 \\
$n_{o}$ & 1.55 & $n_{o}$ & 1.55 \\
$k_{r w}{ }^{*}$ & 0.024 & $k_{r w}{ }^{*}$ & 0.089 \\
$k_{r o}{ }^{*}$ & 0.83 & $k_{r o}{ }^{*}$ & 0.83 \\
$S_{o r}$ & 0.267 & $S_{o r}$ & 0.163 \\
$S_{\text {wirr }}$ & 0.3181 & $S_{\text {wirr }}$ & 0.3181 \\
\hline
\end{tabular}

In the previous equations, the words "high" and "low" in the superscripts indicate the value of the parameter at high and low trapping numbers, respectively. The values at high trapping number are usually assumed and the values at low trapping number can be considered as the values obtained through history-matching the effect of LSWI on the second cycle. It is worth mentioning that $k_{r l}^{o^{\text {high }}}$ was assumed to be 0.2 due to the low water endpoint relative permeability of initial seawater cycle (0.025). Table 8 and Figure 16 show two sets of relative permeability curves before and after exceeding the critical trapping number. The oil recovery and pressure drop match for trapping number effect on the second cycle are shown in Figures 17 and 18, respectively.

The $k_{r}$ and $S_{o r}$ contributions curve for the third and fourth cycles is depicted in Figure 19. The cumulative oil recovery and the overall pressure drop curves using the third approach of the second method are shown in Figures 20 and 21, respectively. Sets of relative permeability curves used in history-matching using this approach are presented in Figure 22 and Table 9. The analysis showed that the coreflood of Chandrasekhar and Mohanty [16] was successfully matched using the third approach of the second method 
TABLE 9: Summary of relative permeability parameters (second method-third approach).

\begin{tabular}{|c|c|c|c|c|}
\hline Injection cycle & $k_{r w}$ & $k_{r o}$ & $n_{w}$ & $n_{o}$ \\
\hline First cycle & 0.025 & 0.203 & 1.30 & 3.50 \\
\hline $\begin{array}{l}\text { Second cycle (LSWI } \\
\text { Effect) }\end{array}$ & 0.024 & 0.830 & 1.70 & 1.55 \\
\hline $\begin{array}{l}\text { Second cycle (trapping } \\
\text { number effect) }\end{array}$ & 0.089 & 0.830 & 1.43 & 1.55 \\
\hline Third cycle & 0.023 & 0.850 & 2.00 & 1.53 \\
\hline Fourth cycle & 0.022 & 0.860 & 2.20 & 1.52 \\
\hline
\end{tabular}

by tuning residual oil saturation and relative permeability curves, including endpoints and Corey's exponents.

\section{Summary and Conclusions}

Oil recovery and pressure drop data for the coreflood of Chandrasekhar and Mohanty [16] were matched successfully using UTCHEM. The main findings of this work are summarized as follows.

(i) Wettability alteration is still believed to be the contributor to the LSWI effect on oil recovery from carbonate rocks.

(ii) History-matching of the LSWI effect on oil recovery is sensitive to residual oil saturation and relative permeability curves.

(iii) Tuning both relative permeability endpoints and Corey's exponents is essential for good historymatching of both oil recovery and pressure drop data.

(iv) Neglecting capillary pressure effect on oil recovery and pressure drop history-matching in case of LSWI is a plausible assumption even if the coreflood is conducted at reservoir rate of $1 \mathrm{ft} /$ day.

(v) Oil relative permeability parameters are more sensitive to LSWI compared to water relative permeability parameters.

(vi) The findings of this paper validate our previous findings [19] upon which the two corefloods of Yousef et al. [7] were history-matched.

Moreover, in light of the previous findings, a simple interpolation model can be implemented in UTCHEM and applied to history-match both works of Yousef et al. [7] and Chandrasekhar and Mohanty [16]. This is our next step to have more insight into the low salinity water injection (LSWI) mechanism before we propose our own mechanistic LSWI model.

\section{Nomenclature}

CPC: Parameter related to the maximum capillary pressure

EPC: Capillary pressure exponent

$k_{r l}^{*}$ : $\quad$ Phase endpoint relative permeability $n_{l}$ : Phase Corey's exponent

$S_{l}$ : Phase saturation

$S_{l r}:$ Phase residual saturation

$\sigma:$ Interfacial tension.

\section{Conflict of Interests}

The authors declare that there is no conflict of interests regarding the publication of this paper.

\section{Acknowledgments}

The authors wish to acknowledge useful discussions with $\mathrm{K}$. $\mathrm{K}$. Mohanty during the work. This work was funded by Abu Dhabi National Oil Company (ADNOC).

\section{References}

[1] E. J. Høgnesen, S. Strand, and T. Austad, "Waterflooding of preferential oil-wet carbonates: oil recovery related to reservoir temperature and brine composition," in Proceedings of the 67th European Association of Geoscientists and Engineers (EAGE '05), pp. 815-823, Madrid, Spain, June 2005, SPE-94166.

[2] K. J. Webb, C. J. J. Black, and G. Tjetland, "A laboratory study investigating methods for improving oil recovery in carbonates," in Proceedings of the International Petroleum Technology Conference, pp. 785-791, Doha, Qatar, November 2005, SPE10506.

[3] P. Zhang, M. T. Tweheyo, and T. Austad, "Wettability alteration and improved oil recovery by spontaneous imbibition of seawater into chalk: impact of the potential determining ions $\mathrm{Ca}^{2+}$, $\mathrm{Mg}^{2+}$, and $\mathrm{SO}_{4}{ }^{2-}$, , Colloids and Surfaces A: Physicochemical and Engineering Aspects, vol. 301, no. 1-3, pp. 199-208, 2007.

[4] S. Strand, T. Austad, T. Puntervold, E. J. Høgnesen, M. Olsen, and S. M. F. Barstad, "'Smart Water' for oil recovery from fractured limestone: a preliminary study," Energy and Fuels, vol. 22, no. 5, pp. 3126-3133, 2008.

[5] I. Fjelde, "Low salinity water flooding experimental experience and challenges," in Proceedings of the Force RP Work Shop: Low Salinity Water Flooding, the Importance of Salt Content in Injection Water, Stavanger, Norway, 2008.

[6] S. Bagci, M. V. Kok, and U. Turksoy, "Effect of brine composition on oil recovery by waterflooding," Petroleum Science and Technology, vol. 19, no. 3-4, pp. 359-372, 2001.

[7] A. A. Yousef, S. Al-Saleh, A. Al-Kaabi, and M. Al-Jawfi, "Laboratory investigation of novel oil recovery method for carbonate reservoirs," in Proceedings of the SPE Canadian Unconventional Resources and International Petroleum Conference, pp. 18251859, Alberta, Canada, October 2010, SPE-137634.

[8] R. Gupta, P. Griffin, L. Hu et al., "Enhanced waterflood for middle east carbonates cores-impact of injection water composition," in Proceedings of the SPE Middle East Oil and Gas Show and Conference, Manama, Bahrain, 2011, SPE-142668.

[9] A. A. Yousef, S. Al-Saleh, and M. Al-Jawfi, "Improved/enhanced oil recovery from carbonate reservoirs by tuning injection water salinity and ionic content," in Proceedings of the SPE Improved Oil Recovery Symposium, Tulsa, Okla, USA, 2012, SPE-154076.

[10] A. S. Al-Harrasi, R. S. Al Maamari, and S. Masalmeh, "Laboratory investigation of low salinity waterflooding for carbonate reservoirs," in Proceedings of the SPE Abu Dhabi International 
Petroleum Exhibition \& Conference, Abu Dhabi, UAE, 2012, SPE-161468.

[11] J. Romanuka, J. P. Hofman, D. J. Ligthelm et al., "Low salinity EOR in carbonates," in Proceedings of the SPE Improved Oil Recovery Symposium, Tulsa, Okla, USA, 2012, SPE-153869.

[12] D. C. Standnes and T. Austad, "Wettability alteration in chalk 2. Mechanism for wettability alteration from oil-wet to water-wet using surfactants," Journal of Petroleum Science and Engineering, vol. 28, no. 3, pp. 123-143, 2000.

[13] P. Zhang, M. T. Tweheyo, and T. Austad, "Wettability alteration and improved oil recovery in chalk: the effect of calcium in the presence of sulfate," Energy and Fuels, vol. 20, no. 5, pp. 20562062, 2006.

[14] T. Puntervold, S. Strand, and T. Austad, "Water flooding of carbonate reservoirs: effects of a model base and natural crude oil bases on chalk wettability," Energy \& Fuels, vol. 21, no. 3, pp. 1606-1616, 2007.

[15] A. A. Yousef, J. Liu, G. Blanchard et al., "Smart water flooding: industry's first field test in carbonate reservoirs," in Proceedings of the SPE Annual Technical Conference and Exhibition, San Antonio, Tex, USA, 2012, SPE-159526.

[16] S. Chandrasekhar and K. K. Mohanty, "Wettability alteration with brine composition in high temperature carbonate reservoirs," in Proceedings of the SPE Annual Technical Conference and Exhibition, New Orleans, La, USA, 2013, SPE-166280.

[17] G. A. Pope, W. Wu, G. Narayanaswamy, M. Delshad, M. M. Sharma, and P. Wang, "Modeling relative permeability effects in gas-condensate reservoirs with a new trapping model," $S P E$ Reservoir Evaluation \& Engineering, vol. 3, no. 2, pp. 171-178, 2000.

[18] M. Delshad, D. Bhuyan, G. A. Pope, and L. Lake, "Effect of capillary number on the residual saturation of a three-phase micellar solution," in Proceedings of the SPE Enhanced Oil Recovery Symposium, Tulsa, Okla, USA, 1986, SPE-14911.

[19] E. W. Al-Shalabi, K. Sepehrnoori, and M. Delshad, "Mechanisms behind low salinity water flooding in carbonate reservoirs," in Proceedings of SPE Western Regional and AAPG Pacific Meeting, Monterey, Calif, USA, 2013, SPE-165339. 

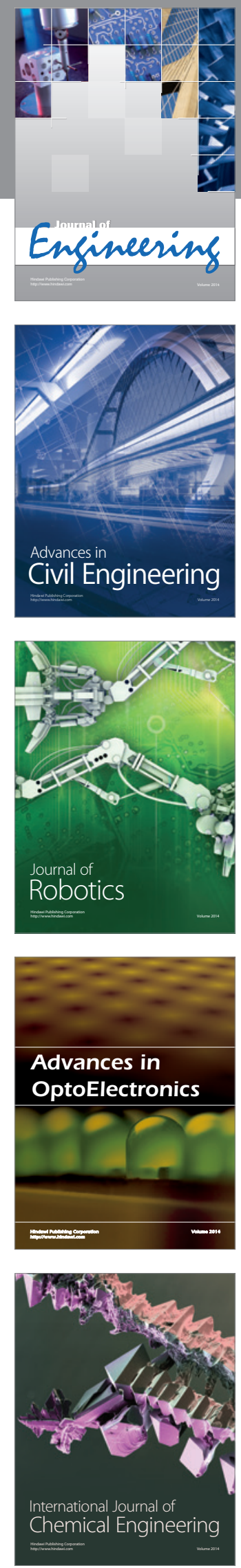

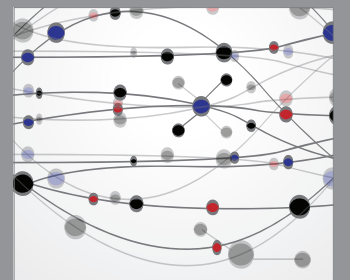

The Scientific World Journal
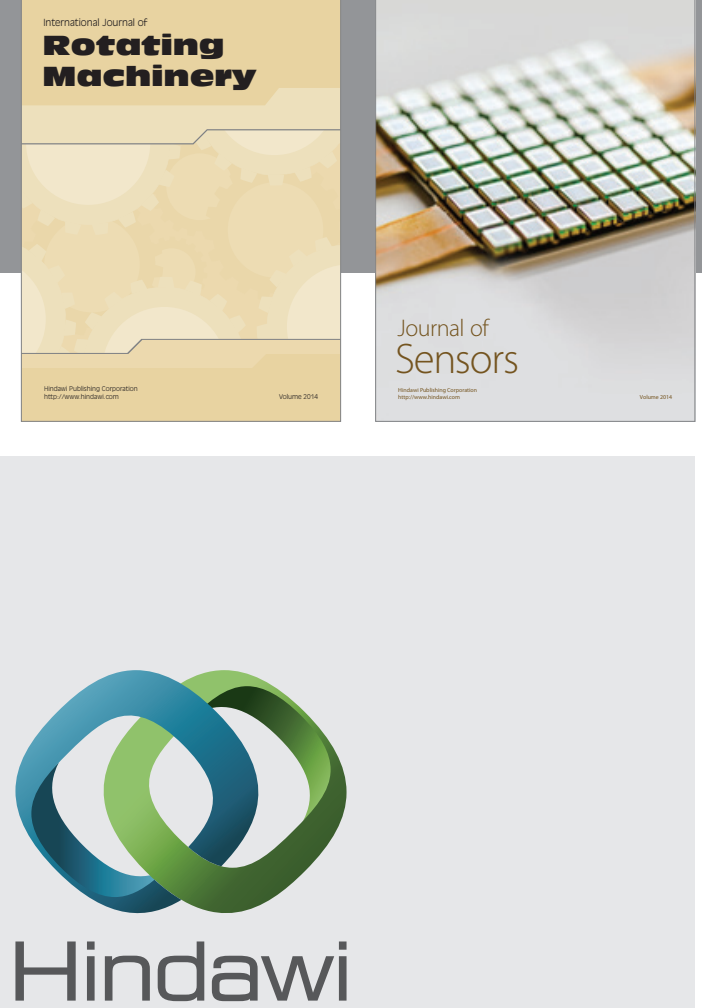

Submit your manuscripts at http://www.hindawi.com
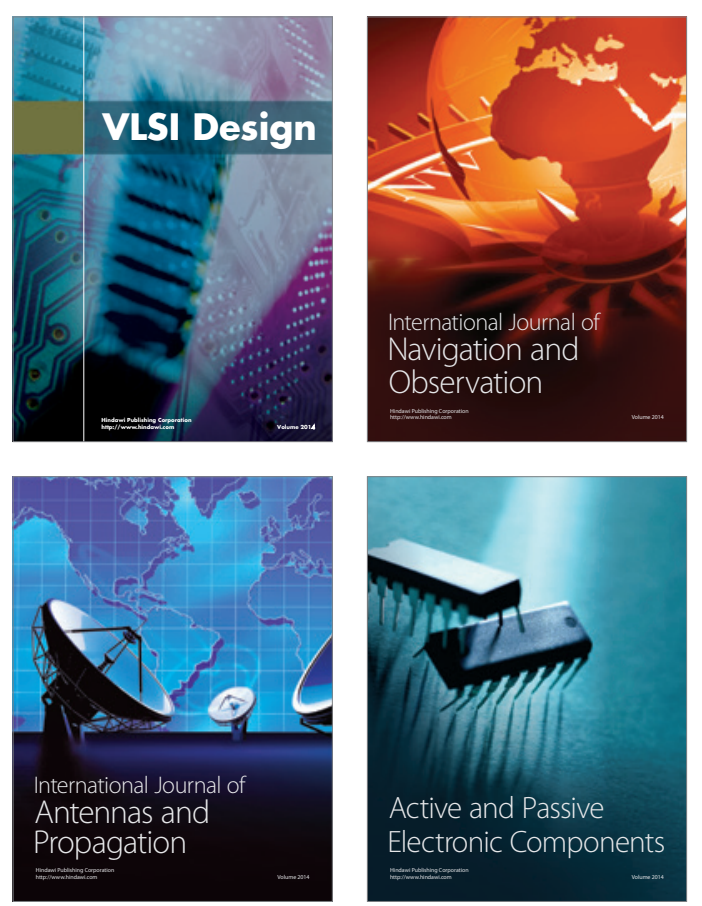
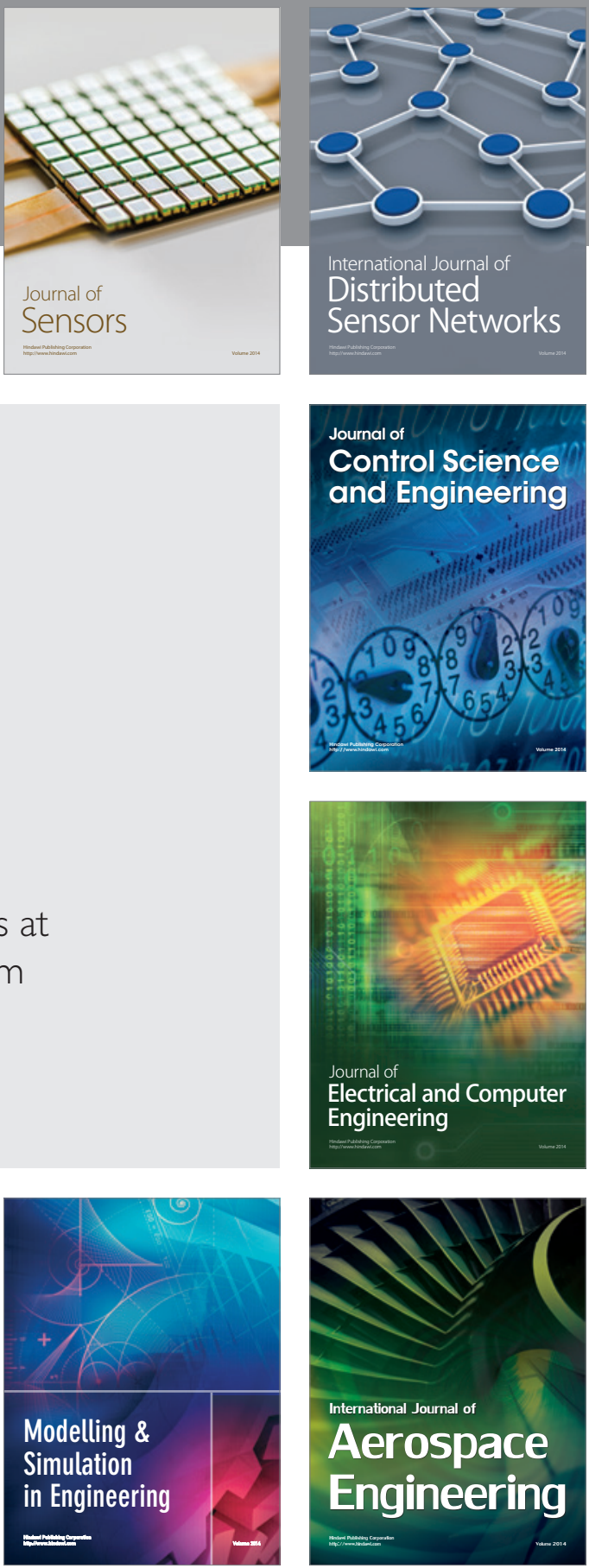

Journal of

Control Science

and Engineering
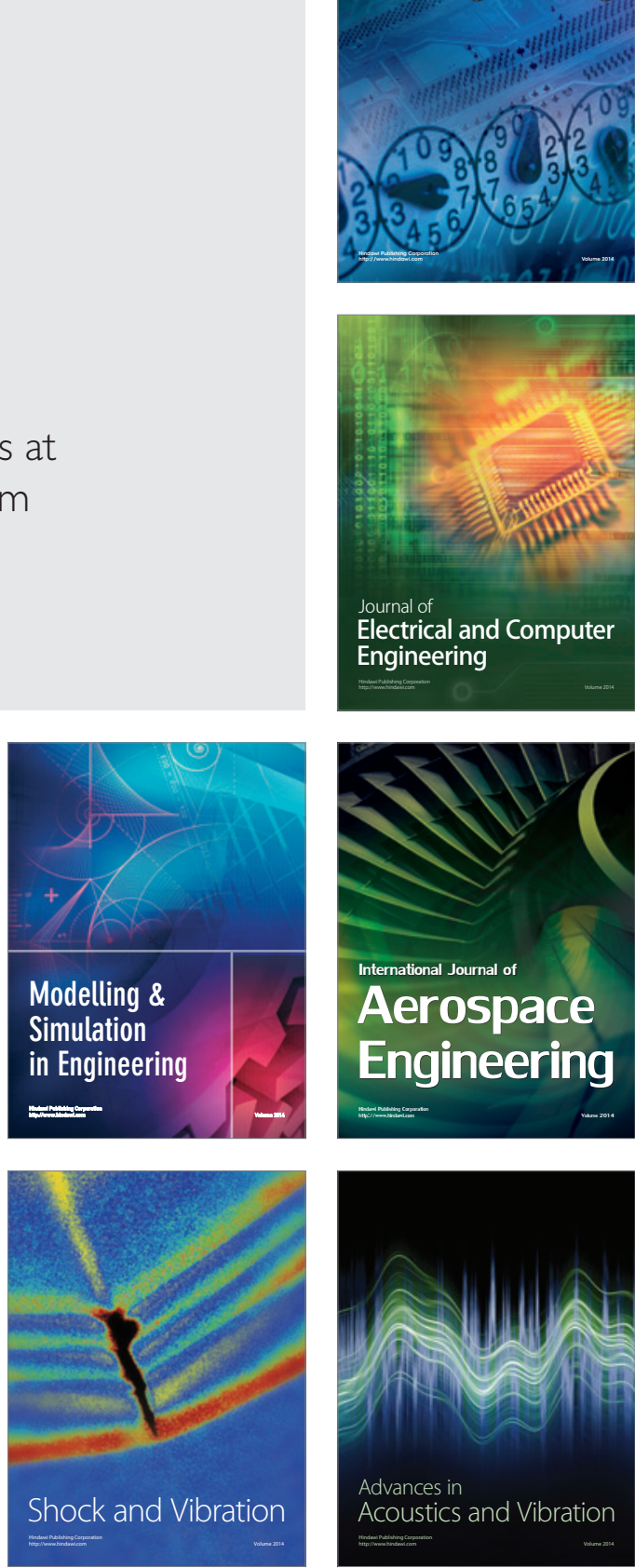